\author{
Adriana Virginia Bonatto
}

Universidad Nacional de La Plata, La Plata, Buenos Aires, Argentina

\title{
Entre lo propio y lo ajeno: modulaciones identitarias fronterizas en Pedro Almodóvar, Eduardo Mendicutti y Luis Antonio de Villena
}

Resumen: Este trabajo se propone leer las novelas El beso del cosaco de Eduardo Mendicutti y Malditos de Luis Antonio de Villena, y las películas La ley del deseo y La mala educación de Pedro Almodóvar, con el objetivo de analizar los modos en que las subjetividades abyectas (que aquí describimos como fronterizas) desafían el orden histórico, político, burgués, católico y heterosexual, que ha dado forma a la identidad colectiva española durante el siglo XX, fuertemente influida por la extensa dictadura de Franco. La puesta en cuestión de los parámetros propios de la normalidad hispánica ocurre a partir del juego con la tensión entre lo propio y lo ajeno, dinámica que abarca también la cuestión de la inteligibilidad del género sexual en relación con las representaciones y las definiciones sobre lo social que dan forma a los imaginarios colectivos e identitarios.

Palabras clave: literatura y cine españoles contemporáneos; género; identidades abyectas; imaginario colectivo español

El lugar de lo abyecto en la cultura depende de las definiciones sobre la normalidad que subyacen a los imaginarios sociales, los cuales operan configurando las representaciones del orden social durante un periodo o corte histórico determinado. Es significativo, y ha llamado mucho la atención de los estudiosos de la cultura española, el modo en que luego de la transición hacia la democracia, dejando atrás un lastre de casi cuarenta años de dictadura, en España salieran a la luz una serie de voces y de personajes (reales y ficticios) que se dedicarían a afirmar la preeminencia del cuerpo, la sexualidad y sus placeres (no heterosexuales, en la mayoría de los casos) como marca de un cambio de época, una vuelta

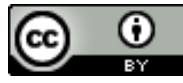

Esta obra está sob licença Creative Commons. 
definitivamente de página y un giro hacia un futuro de libertades y redefiniciones identitarias mucho más saludables. Estas nuevas subjetividades han dado cuenta de los modos en que la identidad colectiva - aquello con lo que cada cual pacta de manera más o menos inconsciente- se nutre de procesos - a veces dolorosos- de exclusión, cuya lógica no replica tanto la división entre lo propio (lo que pertenece a nuestro territorio) y lo ajeno (lo extranjero, aquello de lo que nos diferenciamos) sino, paradójicamente, las relaciones de continuidad entre uno y otro espacio, entre el yo y lo abyecto.

La descripción de algunas de estas subjetividades abyectas, tal como aparecen representadas en personajes de la literatura de Eduardo Mendicutti y de Luis Antonio de Villena y del cine de Pedro Almodóvar, requiere de un compromiso crítico con aquello que, articulado a partir de prácticas no heterocentradas, adquiere características específicamente peninsulares, es decir, solamente comprensibles dentro de ese contexto histórica, cultural y políticamente determinado. En este sentido, preferimos dejar a un lado la utilización, tan frecuente al abordar estos autores o a la estética a la cual subscriben, del adjetivo queer, como término con connotaciones precisas en el ámbito anglosajón que, si bien resulta operativo en tanto nomenclatura para una teoría fundamental sobre las identidades desarrollada en un nivel internacional (no circunscripto, por fortuna, a los Estados Unidos), podría hacernos correr el riesgo de opacar las particularidades de los modos específicos en que las subjetividades otras del ámbito español emergen y se articulan. El componente religioso, por ejemplo, es crucial para entender las inflexiones de la disidencia española, así como también lo son la dicotomía adentro/afuera de España, y el legado moral y cultural franquista que tiñe la vida burguesa, si bien cada vez con menor pregnancia, habilitando un tipo de inteligibilidad cultural única, marcada por binomios tan españoles como los de retraso/modernidad y pasado/presente, que, particularmente en los años setenta y ochenta, determinaron muchas de las decisiones culturales y políticas de la transición a la democracia. En este trabajo nos dedicaremos a pensar en los modos en que los cuerpos otros asumen desafíos de inteligibilidad en relación con el orden histórico, político, burgués, heterosexual y católico, cuestionando ruidosamente a veces esos parámetros propios de la normalidad, y otras alineándose a ellos mediante posiciones performativas y paródicas que dejan al desnudo el carácter construido de las identidades, incluso de las más naturalizadas.

La lectura de una selección de obras de Mendicutti, Almodóvar y de Villena irá mostrando cómo la cuestión de la inteligibilidad del género sexual es fundamental en las representaciones y las definiciones, conscientes e inconscientes, sobre lo social, que dan forma a los imaginarios colectivos e identitarios. De acuerdo con Bronislaw Baczko, los imaginarios sociales operan mediante representaciones totalizantes de la sociedad como un orden, en el cual "cada elemento tiene su lugar, su identidad y su razón de ser," y a partir del cual la colectividad "marca su 'territorio' y las fronteras de éste", define "sus relaciones con los 'otros'" y "forma imágenes de amigos y enemigos, de rivales y aliados" ( BACZKO, 1991 , p. 28). Como componente simbólico del imaginario, el género sexual se constituye en fuerza reguladora y en espacio de definición de la inteligibilidad de los sujetos. Ahora bien, interviniendo con la lógica de lo propio y lo ajeno, el sujeto abyecto (y que escapa a la inteligibilidad heterosexual) viene a exponer, precisamente, la relación necesaria de continuidad entre ambas zonas. En la economía de la heterosexualidad hegemónica, la marca del género, como queda dicho, garantiza la humanización de los cuerpos y el acceso del individuo al estatuto de sujeto por lo que las figuras corporales para las que no pueden asignarse atributos de uno $u$ otro sexo/género forman parte del campo de lo deshumanizado o de lo abyecto (Judith BUTLER, 2007, p. 225). En relación con este término,

1474 Estudos Feministas, Florianópolis, 25(3): 1473-1487, setembro-dezembro/2017 
Butler, inspirándose en Julia Kristeva, sostiene que la distinción binaria entre lo externo al sujeto (lo abyecto o lo otro) y lo interno (lo mismo o lo uno) estabiliza y refuerza al sujeto coherente; pero si ese sujeto es cuestionado, tanto el significado como la necesidad de los términos interno y externo se desplazan, volviéndose dudosa la localización interna de la identidad de género y de la fijeza del yo, y, por lo tanto, problematizándose la relación de exterioridad o de separación entre lo uno y lo abyecto. De hecho, la abyección, como la barrera del yo, de acuerdo con Kristeva, supone la existencia de un "objeto caído" del yo, expulsado, rechazado, pero que no cesa de desafiarlo (KRISTEVA, 2006, p. 8). Por otro lado, abyecto designa al excluido y expulsado de la economía de las identidades que administran la represión del inconsciente para mantenerse estables (KRISTEVA, 2006, p. 1420). En el sistema de la matriz heterosexual, el género que se adapta a las exigencias culturales (en función de la supervivencia estratégica del yo) reniega de la continuidad y del desorden del deseo que, no obstante, incluso en las identidades heterosexuales aparentemente cerradas, logra escaparse y construir su propia lógica (BUTLER, 2007, p. 265-266). ${ }^{~}$ Así, el sujeto coherente y heterosexual existe en virtud de los otros a los que ha tenido que repudiar, es decir, porque ha sabido orientar su deseo para que escapara de formas de amor abyectas u homoeróticas. Ese acto, no obstante, no responde a una voluntad racional, sino que constituye la condición de emergencia del sujeto y el límite de la reflexividad o del conocimiento de sí. Al tiempo que lo inaugura, amenaza también con su disolución.

Durante el análisis, propondremos la caracterización de los personajes en cuestión como representantes de identidades fronterizas, de manera tal de aglutinar mediante ese adjetivo una serie de atributos y de posiciones identitarias (generalmente inestables) que los ubican en zonas intersticiales y desestabilizadoras pero demasiado cercanas a lo propio (la historia reciente, las preferencias y los rituales de las clases medias, el catolicismo como marca de la cultura hispánica, las prerrogativas de género relacionadas con el ser varón y mujer en la cultura española, etc.). En uno de esos casos, como se verá durante el análisis de Malditos, lo fronterizo se construye a partir del desplazamiento geográfico, aunando en una figura profundamente disruptiva la dinámica simbólica de la relación entre lo propio y lo ajeno, lo español y lo foráneo. Sin embargo, como observaremos en los otros ejemplos, la tensión entre lo mismo y lo otro atraviesa estas identidades fronterizas poniendo en evidencia aspectos silenciados, o reprimidos, de la cultura hispánica como sistema heterosexual.

\section{Pedro Almodóvar o la educación de género}

Si hay algo que caracteriza de manera continua la vasta obra de Pedro Almodóvar es ese estilo o ese aire localista que, fuera de España, parece representar, por aglutinación de rasgos, lo español. Pareciera ser que el cine del director manchego rindiera homenaje a cierto tipo de esencia localista conformada por elementos heterogéneos pero claramente asimilables a la cultura popular hispánica: la mujer, tantas veces representada como madre abnegada, la gracia del habla andaluza (presente en personajes, generalmente secundarios, provenientes de Andalucía, que hablan con un acento muy marcado), los

\footnotetext{
1 "[La] producción disciplinaria del género estabiliza falsamente el género para favorecer los intereses de la construcción y la regulación heterosexuales en el ámbito reproductivo. La construcción de la coherencia encubre las discontinuidades de género que están presentes en el contexto heterosexual, bisexual, gay y lésbico, en que el género no es obligatoriamente consecuencia directa del sexo, y el deseo, o la sexualidad en general, no parece ser la consecuencia directa del género; en realidad, donde ninguna de estas dimensiones de corporalidad significativa se manifiestan o reflejan una a otra" (BULER, 2007, p. 265-266).
} 
colores brillantes y mediterráneos de los decorados, y la vitalidad de la imaginería católica, con sus rituales, su vestuario, sus interiores, etc., como marca de las prácticas y preferencias de la pequeña burguesía. Al mismo tiempo, es evidente para el espectador que el cine de Almodóvar (y particularmente su etapa temprana) construye una España personal, que coincide con la imagen de una España, en palabras de Jean Méjean, "totalmente nueva y de lo más in", libre ya del yugo franquista que en los años ochenta, punk y decididamente contestatarios, todavía atravesados por la movida, se pronuncia en contra de su pasado más reciente (MÉJEAN, 2004, p. 21). Esta nueva España está presente en la sexualidad libre que muchos de su protagonistas expresan en los argumentos de sus películas, desatada ya del deber matrimonial; en el protagonismo asignado a personajes travestis y transexuales, y en la representación de las libertades del nuevo ciudadano español en el contexto posfranquista (la vida nocturna en Madrid, el consumo de drogas, la libertad sexual, etc.).

Queremos retener esta caracterización de cine español porque es precisamente ese todo cultural ibérico el que en general en sus películas y en particular en la construcción de algunos de sus personajes aparece dislocado y representado como ficción de identidad. Si algo deja en claro la profusión identitaria de los personajes almodovarianos es que, como explicara Judith Butler mucho después de que aparecieran las primeras películas del joven director, la identidad no es más que el producto de una laboriosa construcción, fundamentada, cuando se trata de identidades heterosexuales, en repeticiones compulsivas y en repudios no asumidos. De allí a la tentación de asociar la estética almodovariana con las manifestaciones tempranas de cierta queerness española hay solo un paso. Intentamos omitirlo, porque consideramos que la riqueza de la representación identitaria de los personajes que analizaremos en este apartado se asocian precisamente a la particularidad de los componentes y rasgos culturales que dentro y fuera de España desde el período franquista en adelante se asociaron con lo español. Este modo de transgredir lo propio es muy similar a aquello que en los años setenta hacía José Ocaña con su arte y sus performances callejeras en Barcelona. De acuerdo con la lectura que de este artista andaluz hace Beatriz Preciado, la producción de Ocaña, situada durante los años de la transición democrática, invita a pensar en los modos en que se construye la relación hegemonía/subalternidad durante ese período crucial de la historia reciente española (PRECIADO, 2011 , p. 74). En las prácticas ocañeras, las nociones de cursi, kitsch y camp, entendidas como signos de subalternidad, son resignificadas y subvertidas (PRECIADO, 2011 , p. 78), de la misma forma que, como sostenemos, ocurre en ciertas escenas del cine almodovariano. Pensemos por ejemplo en las estatuillas de santos que conforman el altar tremendamente kitsch de Tina en La ley del deseo o en la cursilería de sus gestos y vestimenta cuando canta frente al cura sentado al órgano en la iglesia del colegio Ramiro de Maeztu, en una de las escenas que analizaremos: estos signos bastante cercanos a un tipo de representación asociada normalmente a la sensibilidad camp (como forma de expresión propia de las identidades disidentes o queer) portan algo más que precisamente escapa y completa esos significados ligados a la subalternidad encarnados por personajes de este tipo. Se trata de la familiaridad que estas escenas tienen con la identidad pequeño burguesa más amplia, con sus preferencias y sus referentes culturales tal como fueran forjados durante la mayor parte del siglo veinte, en una sociedad que desarrolló sus gustos y sus costumbres culturales bajo la vigilancia de una prolongada dictadura: el melodrama, el catolicismo, los escenarios eclesiásticos, las canciones aprendidas en los colegios cuando la educación católica era la única disponible, la imaginería moral en relación con la figura de la madre y la mujer abnegadas que impulsaba el nacionalcatolicismo especialmente a través de la Sección Femenina, etc.

1476 Estudos Feministas, Florianópolis, 25(3): 1473-1487, setembro-dezembro/2017 
Siguiendo con las elaboraciones de Beatriz Preciado, "cursi, kitsch, camp y queer señalan todo aquello que excede la nueva figura masculina del hombre heterosexual blanco y viril" (PRECIADO, 2011, p. 82). El hecho de que tanto Ocaña como Almodóvar trabajen sobre figuras de travestis y transexuales involucradas en toda esta iconografía hispánica les permite ocupar lugares estratégicos frente a lo que Preciado denomina como la hegemonía nacional católica así como frente a los lenguajes contraculturales de la izquierda que durante la transición adquieren protagonismo (PRECIADO, 2011, p. 86). En suma, las prácticas que describimos expresan los modos en que las minorías subalternas manipulan los materiales de la cultura popular, que a su vez ya habían sido transformados en "baluartes de la hegemonía nacionalcatólica (religiosa, sexual, artística, etc.): la iconografía cristiana, la virilidad y la heterosexualidad entendidas como «naturales»"” (PRECIADO, 2011 , p. 96).

La primera serie de escenas que analizaremos pertenecen a La ley del deseo película de 1987 que marca un salto hacia la popularidad del cine almodovariano-y se inicia con la visita casual de la transexual Tina, representada por Carmen Maura, a la iglesia del colegio Ramiro de Maeztu en Madrid, acompañada por Ada, una niña que tiene a su cargo y que en la ficción resulta ser hija de una mujer cuyo papel representa Bibí Andersen, transexual en la vida real. En este breve episodio, Tina oye los acordes de un canto a la Virgen que solía cantar en el coro cuando asistía de pequeño (cuando era varón) a ese colegio y rememora de a poco la canción, para terminar cantándola mientras se acerca al cura que está sentado al órgano (el actor Germán Cobos), utilizando un tipo de gestualidad y de cadencia corporal que resemblan a las de las divas españolas como Sara Montiel, Lola Flores o Rocío Jurado, tan caras a la imitación en los shows de travestis que durante los años setenta y ochenta proliferaron en Madrid y en Barcelona. Mientras Tina canta, Ada, en el fondo de la escena, se entretiene con una harmónica en una actitud completamente ajena a lo que está sucediendo en el primer plano, y que no es otra cosa que uno de los momentos decisivos en la vida de esta mujer, porque en el diálogo que a continuación sostendrá con el párroco encontrará la clave para un cambio muy positivo a su destino de abyección y segregación. ${ }^{2}$ En esta breve conversación, que también respeta los códigos verbales, visuales y gestuales de las escenas de reencuentro de los amantes en el melodrama (miradas detenidas de reconocimiento, frases cortas y contundentes, sorpresa, recuento de la historia personal ligada a un pasado en común, rechazo o imposibilidad de reanudar la relación pasada, abandono brusco de la sala en clara señal de enojo), Tina confiesa ser ese antiguo alumno varón que cantaba en el coro y que mantuviera una relación amorosa con el cura. El eclesiástico se opone firmemente a que vuelva a participar de sus misas (ella cree que cantar nuevamente en el coro va a devolverle esperanzas) y sentencia: "Si es a Dios a quien buscas, ve a cualquier iglesia. Él está en todas". En la escena siguiente, encontramos a Tina canturreando la melodía de "Oh Virgen más pura" acompañada por la harmónica de Ada mientras preparan la mesa para el almuerzo en familia, junto a un altar improvisado, una "cruz de mayo", tal como Tina le hace saber a su hermano. La actitud alegre de Tina y el aire doméstico de la escena nos muestran que efectivamente ella ha llevado a Dios a su hogar, el único espacio donde puede ser quien es, sin recibir sanciones o rechazos de ese afuera tan hostil para ella. El altar doméstico también está representando la interiorización o la apropiación de aquello que en las comunidades hispánicas cristianas, herederas de las antiguas tradiciones populares,

2 En varios momentos de la película se nos hace ver cómo Tina, en tanto varón transformado en mujer, es objeto de burlas, suspicacia y rechazo por parte de personajes secundarios que representan distintos actores sociales (periodistas, policías, médicos, productores teatrales, abogados, incluso el cura en cuestión). 
simboliza la renovación por la llegada de la primavera. Este giro hiperbólico de Tina hacia la devoción (vemos a medida que avanza la película que el altar va creciendo en cantidad de estatuillas, estampillas de santos y flores) está uniendo en una propuesta transgresiva dos verdades de la identidad hispánica forjadas por el discurso nacional católico: la mujer-madre recluida dentro de su casa, trabajando como sostén moral del hogar y de la nación, y la educación en el catolicismo como única vía de construcción de una España auténtica (recuérdese el énfasis que el nacionalcatolicismo ponía en la recuperación de las tradiciones desplazadas durante el período de la Segunda República). El choque propuesto entre esa mujer percibida por el afuera como falsa (subrayemos que en esta película se pone el acento una y otra vez sobre la tensión autenticidad/inautenticidad de Tina como mujer) y las verdades mencionadas se intensifica a partir la relación causal entre las dos escenas comentadas que el montaje propone. El aprendizaje católico y el aprendizaje de género han sido exitosos, parece decirnos Almodóvar mediante este ejemplo breve pero atravesado por múltiples sentidos, tantos, que casi veinte años más tarde le dedica una película completa: La mala educación. Antes de pasar a este otro film, conviene subrayar que el tema educativo es una de las líneas comunes a las múltiples historias relacionadas con los personajes secundarios de La ley del deseo. Ada ha sido abandonada por su madre, pero a cargo de Tina puede sostener su asistencia a la escuela, incursionar en el teatro, tomar su primera comunión, iniciarse en la devoción por la Virgen, etc. A su vez, Tina ha sido objeto de una educación desviada en manos de su padre y de su mentor espiritual, situación que no es condenada en la película, sino que se acepta (tal como ella lo deja ver en más de una ocasión, pero con especial contundencia en la escena en que le cuenta a su hermano amnésico su pasado como amante del padre de ambos) como parte consustancial de la biografía de este personaje y de su singularidad (en este punto, hay un aspecto trágico en la representación de los personajes trans que se mantiene constante en casi todas las películas de Almodóvar). En otro ejemplo, muy a tono con los toques humorístico-costumbristas tan caros al cine almodovariano, encontramos un inspector de la policía muy cercano a la edad de jubilarse, estereotipo del macho hispánico, que enseña a su hijo, inspector en formación, los gajes del oficio (desde su posicionamiento viril ante las mujeres y ante la misma Tina, hasta las decisiones estratégicas durante la negociación con el secuestrador Antonio).

En La mala educación (2004), Almodóvar se detiene sobre la experiencia de los abusos sexuales dentro de un colegio católico. El resultado es también el cambio de género por parte de la víctima, pero, con mayor dramatismo, esta vez la transformación se acompaña con la caída en las drogas y en la prostitución junto a una acendrada sed de venganza. Ignacio, quien de niño fuera el corista preferido por los curas del colegio salesiano, se dedica de adulta (transformada en Zahara) a repetir ad infinitum la misma escena que aprendiera con sus tutores espirituales, pero cantando boleros e imitando a Sara Montiel en bares nocturnos. Lo inquietante de esta película es el juego de dobles que Almodóvar propone para un mismo personaje: Zahara e lgnacio (la misma persona) son representados por más de un personaje ${ }^{3}$ en función de los distintos niveles de ficción propuestos y de las necesidades del argumento. En La mala educación, la Iglesia también es objeto de crítica, al representarse los efectos que sus rígidas estructuras pueden llegar a tener sobre los sujetos que en sus espacios forjan su identidad. Ignacio niño es objeto de

${ }^{3}$ Gael García Bernal se presenta en principio como Ignacio, y también actúa en el film que se roda dentro del argumento de esta película como Ignacio y como Zahara, pero en verdad él es Juan, hermano de Ignacio, quien es representado porfrancisco Boira. A su vez, en la película rodada dentro de esta historia, Ignacio niño es representado por otro actor, el joven Nacho Pérez. 
deseo sexual por parte de un cura, y todas las manifestaciones litúrgicas que se muestran en esta película deben leerse en ese registro: es el deseo sexual y no la emoción religiosa la que hace temblar al padre Manolo cuando lo escucha entonando el Kyrie Eleison durante la misa. Además, a este niño se lo prepara, o se lo educa, para seducir a los eclesiásticos. En una escena paradigmática, Ignacio es entrenado minuciosamente por otro cura para cantar con la melodía de "Torna a Sorrento" un texto escrito por ellos y destinado al nuevo director del colegio (el padre Manolo). Los movimientos de las manos y las posturas ensayadas, además de la obligación de mirar fijamente al destinatario de esa actuación, funcionan como anticipación perversa de los futuros shows que Ignacio representará de adulto transformado definitivamente en Zahara, y que la película muestra a partir de la actuación del hermano de Ignacio vestido de mujer, con senos y pubis de utilería, durante el rodaje de una escena para la película que cuenta la historia de su hermano. Este personaje femenino (producto de un doble artificio, puesto que se trata de un hombre trasvestido, que a su vez es homosexual - Juan, el hermano de Ignacio, seduce al cura que en el pasado pervirtió a su hermano, así como al mejor amigo de éste, ahora director de cine), tiene, a su vez, rasgos de femme fatale (en este contexto, el opuesto radical de la mujer-madre), los cuales comparte con el actor en cuestión: en este caso, por las características manipuladoras y la frialdad sin límites del muchacho (capaz de engañar, seducir y matar para alcanzar sus objetivos de éxito personal), hablaríamos de enfant terrible. Estos ejemplos dan cuenta no solamente del énfasis puesto en el cine almodovariano sobre el carácter performativo de la identidad genérico sexual (expuesto magistralmente en muchas de sus películas de manera anticipatoria a lo que más adelante fuera estudiado y descrito exhaustivamente por la teoría queer), sino también, en íntima relación con aquél, en las potencialidades educativo-performativas de las instituciones sociales encargadas de modelar el pensamiento y la conducta.

En estas dos muestras del cine de Almodóvar encontramos ejemplos de representación de identidades fronterizas que deben buena parte de sus estrategias de supervivencia a estructuras de poder arraigadas en las bases de lo que normalmente se asocia con la identidad cultural española según fuera forjada por la educación y el discurso nacionalcatólicos. Estos personajes, además, manipulan sabiamente significados y referentes asociados a la cultura popular española, anudando la ficción de identidad genérico-sexual a otros núcleos cohesivos que igualmente son objetos de reconstrucción histórica y política.

\section{El beso del cosaco o la contramemoria}

Uno de los mayores logros de la prosa narrativa de Eduardo Mendicutti radica, a nuestro parecer, en la recuperación que lleva a cabo de historias de vida abyectas inextricablemente ligadas a la historia reciente y al presente españoles, aspecto que debe leerse en el marco de una reflexión hecha en el tiempo presente sobre las tensiones de la memoria colectiva en relación con la normalización del recuerdo y con el problema de los olvidos colectivos. La presencia y la importancia que en sus novelas tiene el pasado reciente, como instancia ineludible en el relato de origen o la historia de vida de la subjetividad abyecta, así como la representación de su memoria a través de personajes literariamente originales y culturalmente abyectos, requiere, en principio, de un detenimiento sobre la tensa relación entre la dictadura y las representaciones normales de lo femenino y lo masculino, teniendo en cuenta que esos cuarenta años de represión y disciplinamiento dieron forma al presente, por más desvinculado o liberado que este último intente representarse en otros medios literarios o culturales. Los modos particulares de la represión y la persecución a la 
disidencia sexual durante el franquismo, que comentaremos a continuación, son distintivos de la sociedad española, aunque comparten algunos puntos en común con la historia reciente de otras sociedades contemporáneas, como la argentina. Aunque en un principio la persecución de la homosexualidad no figuraba entre las acciones más urgentes del Estado franquista, habiendo sido delegado en la lglesia el control de los comportamientos inmorales, mientras el poder político y legal se encargaba de reorganizar un país devastado por la posguerra (Francisco Bastida FREIJEDO, 1986, p. 185), hacia los años cincuenta se produce un cambio sociológico interesante, que coincide ( $y$ debe parte de su origen) con los intentos de la España de Franco de adecuarse a los modelos políticos y económicos internacionales durante la Guerra Fría. A partir de la década del cincuenta, cuando España iniciara su recuperación económica e ingresa en las organizaciones supranacionales como la UNESCO (1952) y la ONU (1955),el modelo hegemónico y fascista de masculinidad belicista y agresiva que había predominado durante la Guerra Civil y los primeros años de la posguerra (antes de la derrota nazi) fue sustituido paulatinamente por el modelo paternalista, con el varón como encargado del sustento de la familia y con una severa vigilancia sobre los comportamientos masculinos que alcanzaría finalmente el ámbito de la legislación (Raquel PLATERO, 2012, p. 182-183). Ese control paranoide lleva a incluir la homosexualidad, en 1954, en la Ley de Vagos y Maleantes y, posteriormente, en la sustituta Ley de Peligrosidad y Rehabilitación Social de 1970. El invertido o el marica, como solían denominarse los comportamientos homoeróticos y transgénero masculinos, recibiría durante el franquismo severos castigos, persecución, aislamiento (además de las penas de prisión, se les prohibía residir en su localidad durante un periodo de dos años), y caería además en una situación abyecta de silenciamiento, tanto historiográfico como literario. La homosexualidad y la transexualidad fueron, durante el franquismo, "una lacra que la sociedad padecía y que el régimen debía eliminar con todos los medios que estaban a su alcance" (Víctor BEDOYA, 2012, p. 165). Para ello, se disponía de un amplio frente de presiones que regulaban y sancionaban los comportamientos sexuales aceptables de acuerdo con normas estrictas relacionadas con los roles de género. De la misma forma en que se sancionaban los desvíos respecto de la norma masculina, también el comportamiento femenino era objeto de una estricta vigilancia. Las esferas social y familiar eran el último reducto de control y vigilancia después de la presión científica, religiosa, moral y legal (Dolores JULIANO, 2012, p. 37). El caso de la homosexualidad femenina, constituye un mundo aparte, por haber sido prácticamente invisibilizada. No había siquiera, por ejemplo, adjetivos que dieran cuenta de sus prácticas y de las personas en ellas involucradas (con excepción de denominaciones pseudocientíficas y provenientes del campo del higienismo y la criminología, pero no popularizadas, como tercer sexo, uranismo o inversión) (JULIANO, 2012, p. 41). Legalmente, incluso, las condenas hacia las mujeres hombrunas se basaban en posibles conductas delictivas, derivadas de su traición al modelo femenino de esposa sumisa y madre, antes que de su comportamiento sexual (JULIANO, 2012, p. 43).

Ante este panorama, las novelas de Mendicutti se abocan a desvelar los secretos y la problemática de la vivencia abyecta durante el pasado franquista, y a exponer las dificultades que aun durante la democracia todavía encuentran quienes no responden a las expectativas normales (heterosexuales) del estatuto social de los géneros femenino y masculino. En la novela que a continuación comentaremos, El beso del cosaco, publicada en el año 2000, Mendicutti lleva a cabo una minuciosa exposición de lo que podríamos denominar como una contramemoria del pasado reciente, mediante el rescate de las formas de amor abyectas. De manera programática, la novela aborda la cuestión todavía no resuelta en la sociedad española del presente, de las memorias desterritorializadas, con una fuerza disruptiva incrementada en la elección de un personaje femenino que revela poco a poco su deseo lesbiano. 
En el último año del siglo XX, agonizando con él, Elsa Sheenan pasa sus últimos días en un hospital de California. En su delirio fantasea con la visita la casa paterna, mansión emplazada junto al Guadalquivir en un pueblo costero de Andalucía, ahora habitada por su hermana y su cuñado, y a donde no había vuelto desde que se fugara en 1938 con su amante norteamericano. Dispuesta a organizar una fiesta de despedida, se reencuentra con su hermana y dialoga con espectros de familiares y de allegados; una de ellas, hija de la criada y antigua amiga de la infancia, primer y único amor de Elsa. Los espectros que visitan a Elsa fallecieron a lo largo del siglo XX por medio de desenlaces trágicos, situación que Elsa vincula con la leyenda del beso del cosaco. Vladimir, o el cosaco, no es otra cosa que una estatua de ébano vestida de guerrero ruso, bastante kitsch, emplazada en el vestíbulo como "centinela (...) [d]el prestigio social del hogar" (Eduardo MENDICUTTI, 2000, p. 152) y que ha sido fuente de fantasías sexuales para los integrantes femeninos y masculinos de la acaudalada familia. La leyenda de que el cosaco deja su marca en el destino trágico de aquellos que, al nacer, fueron besados, trastorna las fantasías de Elsa hasta el punto de tatuarse ella misma la marca fatal en la clavícula. Lo que Elsa no llega a comprender es que la excepcionalidad de las vidas supuestamente elegidas por Vladimir radica en la profunda y abrumadora conexión entre el deseo no normativizado, que se extiende incluso al deseo político disidente, y el carácter opresivo de una moral social heteronormativa y de una historia política para las cuales el "amor sin nombre" (MENDICUTTI, 2000 , p. 201) no tiene otro destino más que el repudio o la muerte.

Al tiempo que rememora las historias de las cartas que Magdalena, su hermana, le escribiera desde Andalucía, Elsa va reconociendo, una a una, las causas de los fatales desenlaces de sus visitantes: Genaro, tío homosexual (y causa de humillación familiar por su "trastorno de homofilia" [MENDICUTTI, 2000, p. 52]), muere apuñalado por su amante, un hombre anarquista, en 1928; Javier, sobrino poeta, muere por no poder expresar en la escritura su verdadero deseo (homosexual), y ser obligado en cambio a una poesía de circunstancias; Teresa, prima de Elsa y miliciana, es fusilada en 1938 por un "piquete de falangistas desbocados que estaban dispuestos a limpiar la ciudad de rojos" (MENDICUTTI, 2000, p. 138), y su hermano, Mariano, se suicida horas más tarde luego de ser obligado a darle el tiro de gracia... ${ }^{4}$ Pero hay dos muertes que se presentan como cruciales para la subjetividad de Elsa. Se trata del trágico accidente de sus sobrinas nietas Laura y Julia, cuya causa Elsa conoce tardíamente, debido a la misteriosa decisión de Magdalena de postergar el envío de una carta, y dársela personalmente. Las dos hermanas, incestuosas y lesbianas ("elegantes, bonitas, lesbianas e incestuosas - dijo [Genaro] con verdadera y muy mundana admiración-. Da gusto verlas" [MENDICUTTI, 2000, p. 197]), se suicidan abrazadas adentro del auto de una de ellas. La revelación acerca de la naturaleza de ese "amor del que Magdalena jamás había hablado o escrito, en el que nunca había querido pensar" (MENDICUTTI, 2000, p. 199) coloca a Elsa frente al espejo de su subjetividad, marcada a fuego por el amor hacia Cari, la hija de la criada de la familia Medina, quien perdiera la vida a los 17 años y quien regresa, junto con los otros, para mostrar a Elsa que el origen de su interminable búsqueda de aventuras radica en el repudio de ese primer amor, también lesbiano, revelación que impone un súbito y melodramático cambio de

${ }^{4}$ Otras de las tantas muertes narradas en la novela son las del artista travestido Pelayo Galván, sobrino de Elsa, quien muere de sida en 1994; la de la niña Cari, hija de la criada de los Medina, quien muere atragantada con una ciruela, y la de Bonifacio, primo de Elsa, quien es ajusticiado en 1944 por otros estraperlistas por su "dadivosidad con los pobres" (MENDICUTTI, 2000, p.173) al facilitarles penicilina en una época en que la supervivencia a la tuberculosis dependía de la pertenencia de clase.

${ }^{5}$ Las citas de esta novela corresponden a la versión Kindle de la misma, por lo que se indica el número de posición de lectura. 
tono en la narración, y en el que se manifiesta plenamente la estilización camp de toda la novela:

Llevo toda mi vida viéndote - dijo Elsa, temblorosa, y sólo ella podía comprender hasta qué extremo decía la verdad.

- El señorito Genaro también me ha dicho que vas a necesitarme.

— Llevo necesitándote toda mi vida (MENDICUTTI, 2000, p. 113).

Lo que esta saga familiar deja en claro es que, desde la óptica propuesta por Mendicutti, hay una continuidad aparentemente irremediable en la historia reciente de España entre la disidencia sexual y la disidencia política, conclusión que es posible derivar de la yuxtaposición aparentemente aleatoria de los destinos trágicos (y besados por Vladimir) expuestos en la novela. Tanto Elsa como sus parientes y conocidos ya desaparecidos forman parte de un conjunto de identidades fronterizas obligadas a pactar con el silencio impuesto por las conveniencias de la moral histórica y burguesa. En las historias trágicas de vida recuperadas por la memoria agonizante de la protagonista, queda claro que el otro silenciado es parte constitutiva de la memoria colectiva, y de su lógica fundamental basada en la tensión entre el recuerdo y el olvido. La indisolubilidad entre dos tipos igualmente repudiados de subversión (la subversión sexual y la política), en el seno de clanes familiares estrictamente conservadores o de identidades situadas en el marco de la moral burguesa y política hegemónicas durante el periodo franquista, permite dar cuenta de una memoria disidente o contramemoria que interactúa, oponiéndose o desenmascarándola, con la memoria colectiva especialmente puesta en circulación (y en cuestión) en el discurso literario, académico y en los medios de comunicación, a partir de la década del noventa, cuando en España ocurre lo que se ha denominado como fenómeno de "explosión memorialística" (COLMEIRO, 2005).

\section{Luis Antonio de Villena o los malditos}

La novela Malditos, publicada en 2010, es otro ejemplo de representación de identidades fronterizas, que ataca de manera frontal los esquemas socioculturales de la vida burguesa. Centrada sobre un personaje ficticio, llamado Emilio Jordán, la novela en verdad propone una reapropiación literaria de la vida del escritor Eduardo Haro lbars, uno de los primeros representantes del malditismo literario del Madrid de los últimos años del franquismo, herederos peninsulares de la generación beat, abanderados de la contracultura radical (diferenciados claramente de los hippies o de los progres de izquierda) y de un modo de vida marcado por la adicción a las drogas, la promiscuidad sexual y la pobreza económica, difícilmente traducible en los términos de los cauces burgueses disponibles para los hombres y las mujeres españoles del tardofranquismo. Emilio Jordán, quien, como su correlato real Haro lbars, muere de sida en 1988, viene a representar, de acuerdo con la mirada adusta de de Villena, la clase de transgresores más drásticos que diera lugar la historia reciente de España y que fuera antecesora de las rupturas liberadoras más generalizadas (culturales y sexuales, principalmente) que el país experimentó durante los años de la Movida, a las cuales, sin embargo, su radicalidad no se compara. No obstante, y a pesar de la admiración profunda del narrador (y doble ficticio de Luis Antonio de Villena), Jordán se condena a sí mismo a un proceso de autodestrucción (un tipo de acabamiento que concuerda con su estatuto de maldito) que culmina con su muerte temprana a los 44 años, y que comparte con toda una galería de personajes secundarios que pueblan esta novela-crónica, de cuyas costumbres y adicciones extremas el narrador intenta permanecer ajeno. Es curiosa esta operación de distanciamiento, así como la manera 
en que convive con la admiración explícita profesada hacia el biografiado. De hecho, el narrador se sabe observador, testigo privilegiado de unos modos de vida que pronto serán parte de una mitología decadente:

Aunque yo me pusiera varios anillos grandes y raros, y adoptara frías poses decadentes, incluso con broches o leontinas, era una mezcla de señorito pirado y extraviado - o que pretendía serlo- en un fin de siglo eterno, y ellos ramas vivas del contraculturalismo, entre rockero y hippy. Ellos eran el presente. Yo me columpiaba entre pasado y futuro (Luis Antonio DE VILLENA, 2014, p. 1031). ${ }^{5}$

Muy probablemente la delimitación de espacios correlativos a la gran subdivisión normalidad/abyección que atraviesa cultural y socialmente las configuraciones de sujeto dentro una España muy atenta a los lineamientos provenientes de la moral nacionalcatólica y en continua negociación con ellos, contribuye a esa necesidad de demarcar para sí un cierto lugar, si bien contestatario, lo suficientemente a resguardo de las autorrepresentaciones ilegibles de esos sujetos abyectos. Por ello, la historia de Emilio Jordán se vincula con un origen, aunque español, foráneo: desde niño vivió con sus abuelos en Tánger, aprendiendo de sus habitantes menos respetables (drogadictos, promiscuos, delincuentes y, principalmente, africanos), así como de escritores y artistas allí radicados (Tenesse Williams, Paul Bowles, Emilio Sanz de Soto, Ángel Vázquez...), las prácticas corporales y literarias que en la metrópoli lo diferenciarán de cualquier representación convencional de sujeto hetero y homosexual. De hecho, Tánger aparece como "la ciudad de la libertad", "ciudad permisiva, viciosa y azul, llena de pecados magníficos y una alta nómina de escritores y aún de pintores, seductora y apetecible in extenso" (DE VILLENA, 2014, p. 528-535), espacio casi mítico en contraste con el pacatismo peninsular de los años sesenta y setenta. El roce temprano con estilos de vida tremendamente dislocados (la novela-crónica insiste en el desborde como modus vivendi de Jordán y de sus contemporáneos, en una suerte de épica de la ruptura moral, sexual y artística) recubre a Emilio Jordán de cierto halo progresista que fascina a sus contemporáneos madrileños. Es interesante que el traspaso de las fronteras de la normalidad burguesa que ocurre a partir de las prácticas sexuales que Emilio mantiene con otros muchachos tangerinos (y que en la novela vendrían a significar rituales de iniciación en la vida fronteriza del joven escritor) se vincula paradójicamente al concepto de masculinidad. Al describir los acoples sexuales entre Emilio adolescente y dos hermanos africanos pobres -el mayor de los cuales era líder de una banda de delincuentes-, el narrador subraya el carácter masculino (en contraposición al término homosexual) de estas orgías familiares:

[...] los tres hermanos Latib varones (había un tercero más pequeño) compartían como era natural el mismo pequeño cuarto de una casa pequeña, y era allí donde muy habitualmente sesteaban o pasaban un rato de la noche, era más que probable que todos vieran y supieran todo. Como en otros hogares. Nada extraño al final. Y quizás alguna tarde de calor, más benéfica al sexo, Emilio sería penetrado por Sadí mientras él penetraba a Simo. Siempre con saliva y nada de homosexualidad. Eso era (tuviese el nombre que tuviera) una feliz y gustosa complicidad entre amigos. Un modo de afirmar: lo conozco todo de ti (y tú de mí y de él), no hay trampas ni mentira. La mano está abierta y franca. El corazón asimismo. Como hermanos. Y esas cosas - juzguemos lo que juzguemos- jamás podían ocurrir con mujeres. Eran un puro universo masculino. Cariñosa y afectiva masculinidad. La palabra homosexualidad — que a Emilio le gustó reivindicar después- allí no tenía sitio. En verdad no hacía falta alguna... (DE VILLENA, 2014, p. 604-611)

El pacto que sellan los participantes de estos encuentros se vincula estrechamente con el concepto de cofradía, que supone la asociación de iguales con fines, en este caso, 
iniciáticos. Esa igualdad se corresponde con el desmarque de estos varones respecto de un otro, calificado como femenino. Incluso con las rotundas diferencias de raza y de clase que separan a Emilio de sus compañeros africanos, el pacto entre iguales supone la equipotencia de lo masculino como tal (por ello el narrador se ocupa de dejar en claro que la homosexualidad no tiene nada que ver con esas prácticas). Paradójicamente, el inicio en la masculinidad más radical (la que involucra la complicidad de los pares o iguales) es también el punto de partida para una vida atravesada por el exceso y el desmarque respecto de cualquier lugar reconocible para la identidad genérico sexual: en el futuro Emilio asumirá comportamientos de homosexual, de bisexual, tendrá una pareja estable masculina, otra femenina, participará de orgías, vestirá como andrógino, etc. Este tipo de torcimiento, que podría describirse como queer, requiere para su análisis la comprensión de lo que en España constituye el otro constitutivo de la normalidad burguesa en un momento histórico dado. En este caso, la contraposición entre lo peninsular y lo extranjero, lo que está fuera del límite territorial occidental, blanco y católico, permite juegos de sentido que recubren la figura de Emilio-migrante de características tremendamente desestabilizadoras.

Es importante, para comprender la configuración radical de este personaje, tener en cuenta ese carácter de dislocado. Si bien Jordán es hijo de un periodista reconocido en la España no franquista del momento (al igual que Haro lbars era hijo de Eduardo Haro Tecglen, uno de los redactores de Triunfo), se encarga de construir un mito de origen en el que África juega un papel decisivo. En este sentido, inserto ruidosamente en un Madrid que en los tardíos años sesenta estaba en la frontera del cambio de época, Jordán es equiparable al cursi tal como lo describiera Gómez de la Serna en 1934 en su Ensayo sobre lo cursi y que recupera Preciado en el estudio ya citado sobre Ocaña: "Para Gómez de la Serna, es cursi todo aquello que escapa de la racionalidad occidental, "de lo rectilíneo, de lo claro, de lo cortado en superficies demasiado evidentes", allí se dan cita, lo oriental y lo arábigo (...), pero también lo femenino y lo amanerado, el sentimiento, el amor" (PRECIADO, 201 1, p. 80). El cursi es la exuberancia y la extranjería frente a la norma masculina blanca y heterosexual centroeuropea (PRECIADO, 201 1, p. 82). La apariencia andrógina de Jordán, así como su promiscuidad sexual, producen un tipo de fascinación que tiene que ver con el enfrentamiento a los propios límites, con el encuentro con ese que pudo traspasar toda frontera, el que se abisma, el que confirma por su radical exterioridad, los límites constitutivos de la subjetividad viable. En la narración, ese tipo de sujeto recibe el calificativo de maldito, anudando así un periodo de la historia cultural reciente española con los antiguos referentes del malditismo literario francés, y ligando también sus orígenes con los referentes de la generación beat (así, el narrador compara a Emilio Jordán y a sí mismo con Rimbaud, Wilde, Genet, Bourroughs, David Bowie, etc.).

La radicalidad de estas configuraciones identitarias cobra fuerza en el contexto histórico y cultural en el que emergen: la España de los años sesenta y setenta, en el periodo tardofranquista previo a la Movida cultural que estallara hacia fines de los setenta y principios de los ochenta. El narrador de Malditos no abandona oportunidad de hacernos saber que la verdadera ruptura sexual y cultural se dio entre los miembros de esta generación beat, y que el temblor posterior de la Movida es sólo una réplica tardía: "[...] una serie de gente (...) que habían sido los más genuinos pioneros de la modernidad española -la que luego reventó con más pluma y algazara en la movida, pero que ellos habían inventado antes con calor y riesgo" (DE VILLENA, 2014, p. 2294). Incluso cabría hablar de una división tripartita en la historia cultural reciente española: generación de los sesenta, movida de los años ochenta y capitalismo finisecular. El profundo desencanto de la pluma villeniana hacia el gregarismo superfluo de la España del presente tiñe su crónica de un dejo melancólico, el cual, al mismo tiempo, contrasta con la imposibilidad de cumplir la utopía 
rupturista encarnada por Emilio Jordán: la autodestrucción aparece como inevitable. De hecho, prácticamente todos los compañeros de aventuras del joven poeta terminan su carrera alocada ya sea en el ostracismo o en la muerte por HIV, por sobredosis, suicidio o extenuación. Así, la crónica sería la de una generación que se comprometió desde la fronteridad absoluta con su propio proceso de destrucción (del cual, ya señalamos, el narrador — también protagonista- ha sabido mantenerse a salvo).

A la postre, surge el interrogante acerca de si es posible sostener la vigencia de una moral tremendamente rupturista, si ella no está condicionada por circunstancias como la energía juvenil o, junto con ella, las limitaciones concretas para las libertades individuales dentro un sistema político dictatorial y católico. El texto de de Villena vendría a contar precisamente esa imposibilidad de continuar viviendo en la frontera: no es casual que todos los personajes jóvenes, compañeros de Jordán, hayan sucumbido en el camino de su desenfreno.

\section{Conclusiones}

En este trabajo intentamos un acercamiento a un conjunto de personajes que han mostrado diversas formas de ser ese otro de lo hispánico-heteronormal, con el objetivo de reflexionar acerca de los modos en que la palabra y el cuerpo fronterizos desafían la inteligibilidad del orden burgués, heterosexual y católico, cuestionando de diversas formas los parámetros de la normalidad. Intentamos dejar relativamente de lado el uso indiscriminado del adjetivo queer, que en muchos momentos habría parecido de gran utilidad para la descripción, pero que no nos habría permitido sugerir la apertura de interrogantes en relación con las posibilidades epistemológicas de la terminología foránea para el análisis de las realidades culturales peninsulares.

A partir de lo expuesto en el análisis de cada autor, vemos cómo las identidades fronterizas entran en íntima relación con la dinámica constitutiva de los imaginarios sociales, de la tensión entre lo propio y lo ajeno. La misma involucra, además de varios aspectos simbólicos de la vida y el orden sociales, aspectos fundamentales relativos a las regulaciones de los sistemas de sexo-género, como lo son la hegemonía del mandato viril en relación con las definiciones de sujeto masculino que han atravesado la cultura española, o los distintos posicionamientos que ha ido adquiriendo el sujeto femenino a lo largo de la historia reciente. En este trabajo centramos nuestra atención en distintas modulaciones identitarias y fronterizas, como la figura de la mujer madre y católica resignificada por un personaje transexual en La ley del deseo, la de femme fatale, también reformulada por la subjetividad trans en La mala educación; la mujer lesbiana, que ha reprimido o escondido su deseo, y que se equipara a toda una serie de personajes que muestran constituciones subjetivas díscolas en relación las regulaciones sexo genéricas operativas durante el franquismo, o que practicaron alguna forma de disidencia política en El beso del cosaco; y, por último, analizamos las características disruptivas de un personaje radicalmente fronterizo como el poeta Emilio Jordán, cuya originalidad se asocia con la extranjería, es decir, la iniciación sexual y cultural por fuera de las fronteras de la España nacional católica en Malditos. La tensión entre lo local y lo foráneo juega un papel crucial en este último personaje. No obstante, las modulaciones identitarias que observamos en los otros personajes también ponen en juego la relación entre ambos espacios, al dar cuenta del modo en que lo abyecto se vincula con el yo; en este caso, con las formas identitarias (hispánicas) normales de las cuales funcionan como su otro constitutivo. Recordemos, en este punto, aquello que Kristeva y luego Butler señalaran como característica de lo abyecto: su capacidad para conmover la fijeza del yo, de poner en duda la localización interna de la 
identidad de género. En otras palabras, la profusión de formas repulsivas para la lógica de la identidad española masculina o femenina normal estaría dando cuenta de los procesos de represión de esos "afectos apasionados" y homoeróticos primordiales en los cuales se basa la heterosexualidad (SIavoj ZIZEK, 2006, p.119) La indecidibilidad y la inconmensurabilidad que vemos en estas identidades fronterizas las ubican en un espacio aparentemente no identitario o no humano. Sin embargo, ellas estarían proyectando, precisamente, esa parte del uno mismo que se ha repudiado, escenificando en figuras a veces extremas o hiperbólicas el artificio identitario de cuño nacional.

\section{Bibliografía}

BACZKO, Bronislaw. Los imaginarios sociales. Memorias y esperanzas colectivas. Buenos Aires: Nueva Visión, 1991.

BASTIDA FREIJEDO, Francisco. Jueces y franquismo. El pensamiento político del Tribunal Supremo en la Dictadura. Barcelona: Ariel, 1986.

BEDOYA, Víctor. "El franquismo contra las transexuales: expedientes policiales y judiciales". In: Raquel Osborne (ed.). Mujeres bajo sospecha. Memoria y sexualidad. 1930-1980. Madrid: Fundamentos, 2012. p. 165-173.

BUTLER, Judith. El género en disputa. El feminismo y la subversión de la identidad. Barcelona: Paidós, 2007.

COLMEIRO, José. Memoria histórica e identidad cultural. De la postguerra a la postmodernidad. Barcelona: Anthropos, 2005.

DE VILLENA, Luis Antonio. Malditos. Barcelona: Ediciones B (Versión Kindle), 2014.

JULIANO, Dolores. "Tiempo de cuaresma. Modelos de sexualidad femenina bajo el franquismo". In: Raquel Osborne (ed.). Mujeres bajo sospecha. Memoria y sexualidad. 1930-1980. Madrid: Editorial Fundamentos, 2012. p. 35-47.

KRISTEVA, Julia. Poderes de la perversión. Ensayo sobre Louis-Ferdinand Céline. Buenos Aires: Siglo XXI, 2007.

MÉJEAN, Jean- Max. Pedro Almodóvar. Barcelona: Ma non Troppo, 2007.

MENDICUTTI, Eduardo. El beso del cosaco. Barcelona: Tusquets, 2000.

PLATERO, Raquel. "«Su gran placer es usar calzoncillos y calcetines»: la represión femenina bajo la dictadura". In: Raquel Osborne (ed.). Mujeres bajo sospecha. Memoria y sexualidad. 1930-1980. Madrid: Editorial Fundamentos, 2012. p. 175-190.

PRECIADO, Beatriz. "La Ocaña que merecemos. Campceptualismo, subalternidad y políticas performativas". In: Pedro G. Romero (ed.). Ocaña: 1973-1983: acciones, actuaciones, activismo. Barcelona: Ediciones Polígrafa, 2011 . p. 72-169.

ZIZEK, Slavoj. Lacrimae rerum. Ensayos sobre cine moderno y ciberespacio. Buenos Aires: Debate, 2006.

[Recebido em 27/05/2016

e aprovado em 09/02/2017]

Betweeen the Self and the Other: Border Identities and Its Modulations in Pedro Almodóvar, Eduardo Mendicutti and Luis Antonio de Villena

Abstract:The purpose of this work is to analyze the ways in which abject subjectivities (described here as border identities) defy the historic, politic, bourgeois, catholic and heterosexual order which has shaped Hispanic collective identity during the twentieth century, strongly influenced by Franco's dictatorship-, in the novels El beso del cosaco, by Eduardo Mendicutti, and Malditos, by Luis Antonio de Villena, and the films La ley del deseo and La mala educación, by Pedro Almodóvar. This works question the parameters of Hispanic normality by presenting a tension between the self 
and the others, which is also related to the problem of the intelligibility of the sexual gender within the representations and definitions of social life that shape the collective and identity imaginaries. Key words: Spanish contemporary literature and cinema; Gender; Abject subjectivities; Spanish collective imaginary

Adriana Virginia Bonatto (virginiabonatto@yahoo.com) es docente e investigadora en la Universidad Nacional de La Plata. Sus investigaciones versan sobre literatura española contemporánea y estudios de género. Ha publicado en revistas y publicaciones de Argentina, Brasil, España, Italia y Francia. Sus labores de investigación están radicadas en el Centro Interdisciplinario de Investigaciones en Género (CINIG) y en el Instituto Interdisciplinario de Investigaciones en Humanidades y Ciencias Sociales (IdIHCS), de la Universidad Nacional de La Plata. 